\title{
Body Composition Indices and Predicted Cardiovascular Disease Risk Profile among Urban Dwellers in Malaysia
}

\author{
Tin Tin Su, ${ }^{1}$ Mohammadreza Amiri, ${ }^{2}$ Farizah Mohd Hairi, ${ }^{1}$ Nithiah Thangiah,, \\ Maznah Dahlui, ${ }^{1}$ and Hazreen Abdul Majid ${ }^{1}$ \\ ${ }^{1}$ Centre for Population Health (CePH), Department of Social and Preventive Medicine, Faculty of Medicine, University of Malaya, \\ 50603 Kuala Lumpur, Malaysia \\ ${ }^{2}$ Department of Development Studies, Faculty of Economics and Administration, University of Malaya, 50603 Kuala Lumpur, Malaysia \\ Correspondence should be addressed to Tin Tin Su; tintinsu03@yahoo.com
}

Received 12 December 2014; Revised 13 January 2015; Accepted 13 January 2015

Academic Editor: Christof Kolb

Copyright (C) 2015 Tin Tin Su et al. This is an open access article distributed under the Creative Commons Attribution License, which permits unrestricted use, distribution, and reproduction in any medium, provided the original work is properly cited.

\begin{abstract}
Objectives. This study aims to compare various body composition indices and their association with a predicted cardiovascular disease (CVD) risk profile in an urban population in Kuala Lumpur, Malaysia. Methods. A cross-sectional survey was conducted in metropolitan Kuala Lumpur, Malaysia, in 2012. Households were selected using a simple random-sampling method, and adult members were invited for medical screening. The Framingham Risk Scoring algorithm was used to predict CVD risk, which was then analyzed in association with body composition measurements, including waist circumference, waist-hip ratio, waist-height ratio, body fat percentage, and body mass index. Results. Altogether, 882 individuals were included in our analyses. Indices that included waist-related measurements had the strongest association with CVD risk in both genders. After adjusting for demographic and socioeconomic variables, waist-related measurements retained the strongest correlations with predicted CVD risk in males. However, body mass index, waist-height ratio, and waist circumference had the strongest correlation with CVD risk in females. Conclusions. The waist-related indicators of abdominal obesity are important components of CVD risk profiles. As waist-related parameters can quickly and easily be measured, they should be routinely obtained in primary care settings and population health screens in order to assess future CVD risk profiles and design appropriate interventions.
\end{abstract}

\section{Introduction}

Obesity, which refers to a state of being overweight from the excessive accumulation of body fat, often leads to a negative effect on health $[1,2]$. Furthermore, obesity has been identified as a strong risk factor for cardiovascular disease (CVD) [3] and metabolic diseases such as diabetes mellitus and hypertension [4]. Several body composition indices have been used as indicators of obesity, including the body mass index (BMI), which is also considered an indicator of various health risks in general [5]. Waist circumference (WC) is another simple measurement that can assess both intra-abdominal fat mass and overall obesity [6]. Other waistrelated obesity parameters include the waist-hip ratio (WHR) and the waist-height ratio (WHtR) [7]. Other risk factors for CVD (e.g., hypertension and diabetes mellitus) and lipid and glucose levels are associated with abdominal adiposity and can be assessed by these waist-related measurements [8-10]. In addition, various techniques and modern devices are available to assess body fat percentage (BF\%) and body compositions, such as the whole-body dual-energy X-ray absorptiometry scan [11] and the bioelectrical impedance analysis method [12].

Future predictions of CVD incidence are essential for the development of preventive public health policies [13]. Therefore, several CVD risk prediction tools have been generated to predict ten-year CVD risk [14-22] and provide evidencebased input for CVD prevention and health system preparedness for imminent noncommunicable disease burden. Among CVD risk prediction models, the Framingham Risk Scoring (FRS) model [14] is preferred and has been widely validated [23-25] in Asian countries such as China [26], Japan [27, 28], Malaysia [29, 30], Thailand [31], Singapore, and Korea [28], and South Asians living in the United 
Kingdom [32]. A recently modified FRS model uses BMI rather than blood lipid levels to predict CVD risk in a primary care setting [21]. This simplified FRS model appears to be a promising tool for prediction of CVD risk in populationbased screening, particularly in low- and middle-income countries that are unprepared for the current increase in CVD.

Previous studies have shown that Asian body compositions and body fat distribution differ from those of Caucasians with the same BMI, with Asians exhibiting higher $\mathrm{BF} \%[33,34]$. Therefore, it is important to determine which body composition parameter correlates with a predicted CVD risk profile. The aim of the present study was to associate various body composition indices with predicted CVD risk profiles in an Asian population using the FRS model in order to estimate ten-year CVD risk among urban dwellers.

\section{Methods}

2.1. Study Population. Data for this study was collected from a household survey conducted within the Community Housing Projects of Metropolitan Kuala Lumpur between February and December 2012. These housing projects were developed in 2000 by the Kuala Lumpur City Hall Squatter Resettlement Program, where applicants are housed based on the following eligibility criteria: (i) married with at least one child; (ii) head of household monthly salary < MYR 2,000; and (iii) do not own any property within $35 \mathrm{~km}$ of Kuala Lumpur. Households from four Community Housing Projects were selected using a simple random-sampling method.

Adults of selected households were invited for medical screening, which included anthropometric measurements and blood sampling conducted by trained research assistants and nurses under the supervision of a medical doctor. Individuals with incidence of CVD (coronary death, myocardial infarction, coronary insufficiency, angina, ischemic stroke, hemorrhagic stroke, transient ischemic attack, peripheral artery disease, or heart failure) were excluded from the study. Written consent was obtained from respondents. Ethics application was approved by University of Malaya Medical Centre Medical Ethics Committee (MEC ref. number 890.161).

2.2. Sample Size Determination. We estimated the sample size using $G^{*}$ Power software (version 3.1.9.2) [35]. As no published evidence on the correlation of body composition with predicted CVD risk was available, we used different correlation coefficients (0.1-0.9) to estimate the sample size. A calculated sample size of 751 participants was estimated to provide $80 \%$ power and type I error of 0.05 .

2.3. Measurements. Height was measured to the nearest $0.1 \mathrm{~cm}$ by a stadiometer (SECA 217; Seca, Hamburg, Germany), and weight was measured to the nearest $0.1 \mathrm{~kg}$ (SECA 813 Digital High Capacity Floor Scale; Seca). BMI was calculated as weight over squared height $\left(\mathrm{kg} / \mathrm{m}^{2}\right)$. BF\% was assessed by bioelectrical impedance analysis using a body composition analyzer (SC-240 MA; Tanita Corp, Tokyo, Japan). Accuracy of this device has been validated in the USA by comparing it with dual-energy $\mathrm{X}$-ray absorptiometry
[36] and is comparable to results from the InBody370 body composition analyzer [37]. We used the single measurement as has been used in previous studies $[37,38]$. Stretch-resistant tape (SECA 201; Seca) was positioned midway between the lowest rib margin and the iliac crest to measure WC, and the widest point of the hip/proximal thigh, just below the gluteal fold, was used to obtain the hip circumference; measurements were to the nearest $1 \mathrm{~mm}$. WHR and WHtR were derived by dividing WC to hip circumference and height, respectively.

The mean arterial blood pressure was calculated from two measurements (Omron HEM 7211; Omron Corp., Kyoto, Japan) taken from the left arm of participants in a seated position. A registered nurse collected blood samples and blood sugar and lipid profiles were assessed on a Dimension Vista 1500 Intelligent Lab System (Siemens, Munich, Bavaria, Germany) in a certified laboratory of a tertiary hospital. Individuals with a nonfasting random blood sugar $\geq 11.0 \mathrm{mmol} / \mathrm{L}$ and/or were under diabetic treatment were considered as diabetic $[39,40]$.

2.4. CVD Risk Profile. Ten-year CVD risk profiles were estimated using the laboratory-based FRS model [21]. This model has been validated in Malaysia with 600 patients attending the Family Medicine Clinic of the tertiary hospital. The authors concluded that CVD events predicted by FRS were only marginally higher than observed $[29,30]$. This model incorporates age (in years), total and high-density lipoprotein cholesterol levels, systolic blood pressure, antihypertensive medication use (obtained from the questionnaire), smoking status ( $\geq 1$ cigarette per day), and diabetic status. The CVD risk profile was assessed by summing the FRS points derived from each individual's variables converting them into a CVD risk percentage. The general cardiovascular risk prediction charts and detailed discussion can be found in D'Agostino Sr. et al. [21].

2.5. Demographic and Socioeconomic Variables. Demographic and socioeconomic information were collected, such as age, gender, ethnicity/race, marital status, highest education level (none $=0 \mathrm{y}$, primary $=1-6 \mathrm{y}$, secondary $=7-12 \mathrm{y}$, or tertiary $\geq 13$ y of education), monthly income level ( $<1000,1000-1999$, 2000-2999, and $\geq 3000$ MYR), and occupational status (e.g., paid-employee, self-employed, inactive [including retired], homemaker, student, and traineeship or apprenticeship [41, 42]).

2.6. Statistical Analysis. All statistical analyses were performed using Stata v11.2 software (StataCorp, College Station, TX, USA). The demographic and socioeconomic characteristics are presented as a percentage, and measured indices are presented as mean \pm standard deviation. Differences between and among categories were assessed with Student's $t$-tests and analyses of variance. Pearson correlation analyses were used to evaluate associations of body composition indices with the predicted CVD risk. Correlation coefficients were adjusted for demographic and socioeconomic variables (adjusted correlation analysis). For all analyses, $P<0.05$ was considered as statistically significant. 


\section{Results}

We invited 2360 adults ( $\geq 18$ years old) from 833 selected households to participate in anthropometric measurements and blood sampling; the response rate was $50.5 \%$. There was no difference between respondents and nonrespondents with respect to age, gender, or ethnicity. To evaluate the ten-year CVD risk profile, respondents $<30 \mathrm{y}$ and who had $\geq 1 \mathrm{CVD}$ incidence were excluded. A total of 882 respondents with a mean age of $48.1 \pm 11.7 \mathrm{y}$ were included in the analyses.

Table 1 shows the characteristics of the sample population and the mean of predicted CVD risk according to demographic and socioeconomic variables. Males had significantly higher CVD risk compared to females. In addition, significant differences in CVD risk were observed according to age, education, occupation, and marital status (all $P<0.05$ ). However, there was no ethnic difference in predicted CVD risk.

The correlation analysis (Table 2) illustrated significant associations between body composition parameters and predicted CVD risk. In both males and females, CVD risk was most strongly correlated to WHR and WHtR (all $P<0.001$ ). In addition, WC was strongly correlated with CVD risk in both males and females, as was $\mathrm{BF} \%$, though to a lesser extent.

CVD risk was also assessed according to body composition measures after adjusting for age, ethnicity, marital status, education level, occupation status, and income level, as well as by gender (Table 3). In males, WHR had the strongest correlation with ten-year CVD risk, followed by WC and WHtR, whereas BMI had the strongest association in females, followed by WHtR and WC (all $P<0.001$ ). Overall, WC had the strongest correlation with CVD risk, followed by WHtR and BMI (all $P<0.001)$.

\section{Discussion}

The results of this study demonstrate that waist-related indicators of abdominal obesity are significant risk factors for CVD. These indices (i.e., WHR, WHtR, and WC) were strongly associated with cardiovascular risk in both genders. In various nationally representative studies conducted in Malaysia, Malays were shown to have the highest prevalence of CVD risk factors compared to other ethnic groups [43-45], and those residing in urban areas were more likely than other ethnicities to experience one of the CVD risk factors [46]. In contrast, our results indicate that in the next ten years, the risk of CVD might not differ among ethnic groups in urban Malaysia.

Our findings in men are in line with previous studies in which WHR was a reliable factor for evaluating chronic disease and CVD risk $[47,48]$ and long-term CHD and CVD incidence [2, 49-52]. In addition, a previous study claimed that waist-related indices are useful for predicting CVD risk and life-style determinants [53]. Several other studies have suggested that WHtR is the strongest anthropometric indicator for development of CVD or coronary heart disease (CHD) [54-56]. Furthermore, a study in Taiwan found that WHtR had the strongest correlation with CVD risk factors compared to other indices [57]. This is supported by a meta-analysis showing that WHtR has the strongest
TABLE 1: Characteristics and predicted cardiovascular disease (CVD) risk $(n=882)$.

\begin{tabular}{|c|c|c|}
\hline Characteristic & Value & $\begin{array}{l}\text { Predicted CVD risk } \\
\text { mean ( } 95 \% \\
\text { confidence interval) }\end{array}$ \\
\hline \multicolumn{3}{|l|}{ Age, $y$} \\
\hline 30 to 39 & $228(22.85)$ & $3.77(3.31-4.24)$ \\
\hline 40 to 49 & $287(32.54)$ & $9.01(8.16-9.86)$ \\
\hline 50 to 59 & $209(23.70)$ & $15.50(14.25-16.76)$ \\
\hline$\geq 60$ & $158(17.91)$ & $21.00(19.62-22.38)$ \\
\hline$F$-test (prob.) & & $201.08^{* *}$ \\
\hline \multicolumn{3}{|l|}{ Gender } \\
\hline Male & $374(42.40)$ & $15.59(14.59-16.60)$ \\
\hline Female & $508(57.60)$ & $8.21(7.51-8.91)$ \\
\hline$t$-test (prob.) & & $12.21^{* *}$ \\
\hline \multicolumn{3}{|l|}{ Ethnicity } \\
\hline Malaysian & $723(81.97)$ & 11.09 (10.41-11.78) \\
\hline Indian & $144(16.33)$ & $12.36(10.62-14.10)$ \\
\hline Chinese/Others & $15(1.70)$ & $13.62(7.85-19.39)$ \\
\hline$F$-test (prob.) & & 1.48 \\
\hline \multicolumn{3}{|l|}{ Education } \\
\hline None & $70(8.16)$ & $15.65(13.14-18.16)$ \\
\hline Primary & $195(22.73)$ & $14.25(12.83-15.68)$ \\
\hline Secondary & $551(64.22)$ & $9.70(8.98-10.42)$ \\
\hline Tertiary & $42(4.90)$ & $6.00(3.82-8.19)$ \\
\hline$F$-test (prob.) & & $22.67^{* *}$ \\
\hline \multicolumn{3}{|l|}{ Income, MYR } \\
\hline$<1000$ & $168(19.05)$ & $12.52(10.96-14.08)$ \\
\hline 1000-1999 & $352(39.91)$ & $10.73(9.75-11.71)$ \\
\hline 2000-2999 & $205(23.24)$ & $10.55(9.30-11.80)$ \\
\hline$\geq 3000$ & $133(15.08)$ & $10.76(9.28-12.24)$ \\
\hline$F$-test (prob.) & & 1.76 \\
\hline \multicolumn{3}{|l|}{ Occupation } \\
\hline Paid-employee & $332(38.69)$ & $9.16(8.28-10.04)$ \\
\hline Self-employed & $131(15.27)$ & $13.44(11.68-15.21)$ \\
\hline Homemaker & $223(25.99)$ & 7.40 (6.49-8.31) \\
\hline Other & $126(14.69)$ & $16.07(14.28-17.86)$ \\
\hline Inactive & $46(5.36)$ & $21.65(19.18-24.12)$ \\
\hline$F$-test (prob.) & & $45.53^{* *}$ \\
\hline \multicolumn{3}{|l|}{ Marital status } \\
\hline Married & $659(76.81)$ & $8.29(6.47-10.11)$ \\
\hline Divorced & $71(8.28)$ & $11.04(10.32-11.76)$ \\
\hline Widow/widower & $55(6.41)$ & $11.90(9.64-14.15)$ \\
\hline Single & $73(8.51)$ & $13.61(10.82-16.41)$ \\
\hline$F$-test (prob.) & & $3.71^{*}$ \\
\hline Hypertension & $421(47.8)$ & \\
\hline Diabetes & $157(17.8)$ & \\
\hline Smoking & $153(17.4)$ & \\
\hline Body mass index & $27.1(5.8)$ & \\
\hline Body fat percentage & $32.4 \pm 10.8$ & \\
\hline Waist-hip ratio & $0.9 \pm 0.1$ & \\
\hline Waist-height ratio & $0.6 \pm 0.1$ & \\
\hline Waist circumference, & $88.6 \pm 12.5$ & \\
\hline
\end{tabular}

Data are resented as mean \pm standard deviation or as $n(\%) ;{ }^{*} P<0.05 ;{ }^{* *} P$ $<0.001$. 
TABLE 2: Correlations between ten-year cardiovascular disease (CVD) risk and body composition measures.

\begin{tabular}{|c|c|c|c|c|c|c|}
\hline \multirow{3}{*}{ Measure } & \multicolumn{6}{|c|}{ Predicted CVD risk } \\
\hline & \multicolumn{2}{|c|}{ Males } & \multicolumn{2}{|c|}{ Females } & \multicolumn{2}{|c|}{ Total } \\
\hline & $r$ & $P$ & $r$ & $P$ & $r$ & $P$ \\
\hline BMI & 0.0639 & 0.2197 & 0.1686 & $<0.001$ & 0.0377 & 0.2639 \\
\hline $\mathrm{BF} \%$ & 0.1366 & $<0.01$ & 0.1749 & $<0.001$ & -0.1504 & $<0.001$ \\
\hline WHR & 0.4321 & $<0.001$ & 0.2769 & $<0.001$ & 0.4356 & $<0.001$ \\
\hline WHtR & 0.3133 & $<0.001$ & 0.3540 & $<0.001$ & 0.2295 & $<0.001$ \\
\hline WC & 0.2753 & $<0.001$ & 0.2664 & $<0.001$ & 0.2795 & $<0.001$ \\
\hline
\end{tabular}

$\mathrm{BF} \%$ = body fat percentage; $\mathrm{BMI}=$ body mass index; $\mathrm{WC}=$ waist circumference; $\mathrm{WHR}=$ waist-hip ratio; $\mathrm{WH}$ tR = waist-height ratio.

TABLE 3: Adjusted correlations between ten-year cardiovascular disease (CVD) risk and body composition measures.

\begin{tabular}{|c|c|c|c|c|c|c|}
\hline \multirow{3}{*}{ Measure } & \multicolumn{6}{|c|}{ Predicted CVD risk } \\
\hline & \multicolumn{2}{|c|}{ Males $^{1}$} & \multicolumn{2}{|c|}{ Females $^{1}$} & \multicolumn{2}{|c|}{ Total $^{2}$} \\
\hline & $r$ & $P$ & $r$ & $P$ & $r$ & $P$ \\
\hline BMI & 0.1281 & $<0.05$ & 0.2715 & $<0.001$ & 0.2037 & $<0.001$ \\
\hline $\mathrm{BF} \%$ & 0.1310 & $<0.05$ & 0.2257 & $<0.001$ & 0.1842 & $<0.001$ \\
\hline WHR & 0.2217 & $<0.001$ & 0.1119 & $<0.05$ & 0.1602 & $<0.001$ \\
\hline WHtR & 0.1816 & $<0.001$ & 0.2682 & $<0.001$ & 0.2180 & $<0.001$ \\
\hline WC & 0.2011 & $<0.001$ & 0.2655 & $<0.001$ & 0.2331 & $<0.001$ \\
\hline
\end{tabular}

$\mathrm{BF} \%$ = body fat percentage; $\mathrm{BMI}=$ body mass index; $\mathrm{WC}=$ waist circumference; $\mathrm{WHR}=$ waist-hip ratio; $\mathrm{WHtR}=$ waist-height ratio.

${ }^{1}$ Adjusted for age, ethnicity, occupation, marital status, income level, and education level; ${ }^{2}$ adjusted for all plus gender.

relationship with CVD risk factors, particularly with obesity, hypertension, and dyslipidemia, compared to other body composition measurements [47]. In addition, WHR and WC had stronger associations with predicted risk of myocardial infarction than BMI $[2,58,59]$.

The simplest anthropometric index, WC, was one of the body composition measurements that was most strongly associated with risk in both pre- and postadjusted correlation analyses, consistent with previous findings of CVD $[60,61]$ and CHD $[54,55]$. However, in contrast to the present results, other studies found that WC was stronger than WHR and BMI in women $[62,63]$ and has direct effects on long-term CHD and CVD $[2,49-52]$.

The association of BMI with vascular diseases is varied. Wilson et al. [1] concluded that higher BMI levels can be considered as a risk determinant for CHD. Other studies found direct associations between high BMIs and incidence and mortality of CHD in both genders $[1,2,50,52,64]$. However, in our study, there was a weak correlation between BMI and CVD in men, but BMI was associated with CVD risk in females, which is also in line with previous studies conducted in Canada [60]. However, the PROCAM study found that the BMI by itself did not contribute to CVD risk but rather may mediate the effect of other risk factors [52].

$\mathrm{BF} \%$ has been considered the best estimate of an individual's body fat and future risk of CVD $[65,66]$. In our analyses, however, $\mathrm{BF} \%$ was only weakly associated with predicted CVD risk compared to other body composition indices. Another previous study also found that BMI and WHR were better predictors of CVD risk than BF\% [67]. It is possible that $\mathrm{BF} \%$ is only an important contributor to $\mathrm{CVD}$ risk in obese individuals [68].

\section{Conclusion}

This study demonstrates that waist-related body composition indices are associated with predicted CVD risk among urban dwellers in Malaysia. As these parameters are simple and quick to obtain, they should be routinely recorded in the primary care setting and in population-based health screening in order to assess future CVD risk and design appropriate interventions.

\section{Abbreviations \\ BF\%: Body fat percentage \\ BMI: Body mass index \\ CHD: Coronary heart disease \\ CVD: Cardiovascular disease \\ FRS: Framingham Risk Scoring model \\ WC: Waist circumference \\ WHR: Waist-hip ratio \\ WHtR: Waist-height ratio.}

\section{Conflict of Interests}

The authors declare that they have no competing interests.

\section{Authors' Contribution}

Tin Tin Su and Hazreen Abdul Majid conceived and designed the study; Tin Tin Su, Hazreen Abdul Majid, Farizah Mohd Hairi, Maznah Dahlui, and Nithiah Thangiah were involved 
in data collection; Mohammadreza Amiri conducted statistical analyses. All authors were responsible for the drafting of this paper and approved the final paper.

\section{Acknowledgments}

This research was supported by University of Malaya, Flagship project FL009-2011. The authors thank the authorities from the City Hall Kuala Lumpur, Community Housing Management Committee, the participants of the study, and the "PARTNER" research team.

\section{References}

[1] P. W. Wilson, R. B. D’Agostino, L. Sullivan, H. Parise, and W. B. Kannel, "Overweight and obesity as determinants of cardiovascular risk: the Framingham experience," Archives of Internal Medicine, vol. 162, no. 16, pp. 1867-1872, 2002.

[2] H. B. Hubert, M. Feinleib, P. M. McNamara, and W. P. Castelli, "Obesity as an independent risk factor for cardiovascular disease: a 26-year follow-up of participants in the Framingham Heart Study," Circulation, vol. 67, no. 5, pp. 968-977, 1983.

[3] A. Pajak, K. Kuulasmaa, J. Tuomilehto, and E. Ruokokoski, "Geographical variation in the major risk factors of coronary heart disease in men and women aged 35-64 years: the WHO MONICA Project/prepared by Andrzej Pajak...[et al.]," Relation, vol. 41, no. 3-4, pp. 115-140, 1988.

[4] A. E. Field, E. H. Coakley, A. Must et al., "Impact of overweight on the risk of developing common chronic diseases during a 10year period," Archives of Internal Medicine, vol. 161, no. 13, pp. 1581-1586, 2001.

[5] G. A. Bray, "Clinical evaluation of the obese patient," Bailliere's Best Practice in Clinical Endocrinology and Metabolism, vol. 13, no. 1, pp. 71-92, 1999.

[6] J. C. Seidell, P. Bjorntorp, L. Sjöström, R. Sannerstedt, M. Krotkiewski, and H. Kvist, "Regional distribution of muscle and fat mass in men-new insight into the risk of abdominal obesity using computed tomography," International Journal of Obesity, vol. 13, no. 3, pp. 289-303, 1989.

[7] S. C. Ho, Y. M. Chen, J. L. F. Woo, S. S. F. Leung, T. H. Lam, and E. D. Janus, "Association between simple anthropometric indices and cardiovascular risk factors," International Journal of Obesity, vol. 25, no. 11, pp. 1689-1697, 2001.

[8] L.-O. Ohlson, B. Larsson, K. Svardsudd et al., "The influence of body fat distribution on the incidence of diabetes mellitus. 13.5 Years of follow-up of the participants in the study of men born in 1913," Diabetes, vol. 34, no. 10, pp. 1055-1058, 1985.

[9] M.-C. Pouliot, J.-P. Després, S. Lemieux et al., "Waist circumference and abdominal sagittal diameter: best simple anthropometric indexes of abdominal visceral adipose tissue accumulation and related cardiovascular risk in men and women," The American Journal of Cardiology, vol. 73, no. 7, pp. 460-468, 1994.

[10] B. Richelsen and S. B. Pedersen, "Associations between different anthropometric measurements of fatness and metabolic risk parameters in non-obese, healthy, middle-aged men," International Journal of Obesity, vol. 19, no. 3, pp. 169-174, 1995.

[11] R. B. Mazess, H. S. Barden, J. P. Bisek, and J. Hanson, "Dualenergy x-ray absorptiometry for total-body and regional bonemineral and soft-tissue composition," The American Journal of Clinical Nutrition, vol. 51, no. 6, pp. 1106-1112, 1990.
[12] U. G. Kyle, I. Bosaeus, A. D. De Lorenzo et al., "Bioelectrical impedance analysis-part I: review of principles and methods," Clinical Nutrition, vol. 23, no. 5, pp. 1226-1243, 2004.

[13] S. C. Smith Jr., R. Jackson, T. A. Pearson et al., "Principles for national and regional guidelines on cardiovascular disease prevention: a scientific statement from the World Heart and Stroke Forum," Circulation, vol. 109, no. 25, pp. 3112-3121, 2004.

[14] P. W. F. Wilson, R. B. D’Agostino, D. Levy, A. M. Belanger, H. Silbershatz, and W. B. Kannel, "Prediction of coronary heart disease using risk factor categories," Circulation, vol. 97, no. 18, pp. 1837-1847, 1998.

[15] G. Assmann, P. Cullen, and H. Schulte, "Simple scoring scheme for calculating the risk of acute coronary events based on the 10-year follow-up of the Prospective Cardiovascular Münster (PROCAM) study," Circulation, vol. 105, no. 3, pp. 310-315, 2002.

[16] R. M. Conroy, K. Pyörälä, A. P. Fitzgerald et al., "Estimation of ten-year risk of fatal cardiovascular disease in Europe: the SCORE project," European Heart Journal, vol. 24, no. 11, pp. 9871003, 2003.

[17] B. Williams, N. R. Poulter, M. J. Brown et al., "Guidelines for management of hypertension: report of the fourth working party of the Bristish Hypertension Society, 2004-BHS IV," Journal of Human Hypertension, vol. 18, no. 3, pp. 139-185, 2004.

[18] J. Hippisley-Cox, C. Coupland, Y. Vinogradova, J. Robson, M. May, and P. Brindle, "Derivation and validation of QRISK, a new cardiovascular disease risk score for the United Kingdom: prospective open cohort study," British Medical Journal, vol. 335, no. 7611, pp. 136-141, 2007.

[19] M. Woodward, P. Brindle, and H. Tunsfall-Pedoe, "Adding social deprivation and family history to cardiovascular risk assessment: the ASSIGN score from the Scottish Heart Health Extended Cohort (SHHEC)," Heart, vol. 93, no. 2, pp. 172-176, 2007.

[20] World Health Organization, Prevention of Cardiovascular Disease: Pocket Guidelines for Assessment and Management of Cardiovascular Risk: (WHO/ISH Cardiovascular Risk Prediction Charts for the European Region), 2007.

[21] R. B. D’Agostino Sr., R. S. Vasan, M. J. Pencina et al., "General cardiovascular risk profile for use in primary care: the Framingham heart study," Circulation, vol. 117, no. 6, pp. 743-753, 2008.

[22] J. Hippisley-Cox, C. Coupland, Y. Vinogradova et al., "Predicting cardiovascular risk in England and Wales: prospective derivation and validation of QRISK2," The British Medical Journal, vol. 336, no. 7659, pp. 1475-1482, 2008.

[23] R. B. D’Agostino Sr., S. Grundy, L. M. Sullivan, P. Wilson, and Group CHDRP, "Validation of the Framingham coronary heart disease prediction scores: results of a multiple ethnic groups investigation," The Journal of the American Medical Association, vol. 286, no. 2, pp. 180-187, 2001.

[24] G. Icaza, L. Núñez, J. Marrugat et al., "Estimation of coronary heart disease risk in Chilean subjects based on adapted Framingham equations," Revista Médica de Chile, vol. 137, no. 10, pp. 1273-1282, 2009.

[25] E. Zomer, A. Owen, D. J. Magliano, D. Liew, and C. Reid, "Validation of two Framingham cardiovascular risk prediction algorithms in an Australian population: the 'old' versus the 'new' Framingham equation," European Journal of Cardiovascular Prevention and Rehabilitation, vol. 18, no. 1, pp. 115-120, 2011.

[26] J. Liu, Y. Hong, R. B. D’Agostino Sr. et al., "Predictive value for the Chinese population of the Framingham CHD risk assessment tool compared with the Chinese Multi-provincial 
Cohort Study," Journal of the American Medical Association, vol. 291, no. 21, pp. 2591-2599, 2004.

[27] M. Suka, H. Sugimori, and K. Yoshida, "Validity of the Framingham risk model applied to Japanese men," Methods of Information in Medicine, vol. 41, no. 3, pp. 213-215, 2002.

[28] Asia Pacific Cohort Studies Collaboration, F. Barzi, A. Patel et al., "Cardiovascular risk prediction tools for populations in Asia," Journal of Epidemiology and Community Health, vol. 61, no. 2, pp. 115-121, 2007.

[29] K. K. Ng and Y. C. Chia, "Utility of Framingham's model in predicting coronary heart disease risk in Malaysia, a developing country," Atherosclerosis Supplements, vol. 9, no. 1, p. 92, 2008.

[30] Y. C. Chia, C. A. Jenkins, and S. Y. W. Tang, "318 Validation of the Framingham general cardiovascular risk prediction score in a multi-ethnic primary care cohort," Journal of Hypertension, vol. 30, article e93, 2012.

[31] P. Sritara, S. Cheepudomwit, N. Chapman et al., "Twelve-year changes in vascular risk factors and their associations with mortality in a cohort of 3499 Thais: the Electricity Generating Authority of Thailand Study," International Journal of Epidemiology, vol. 32, no. 3, pp. 461-468, 2003.

[32] R. Bhopal, C. Fischbacher, E. Vartiainen, N. Unwin, M. White, and G. Alberti, "Predicted and observed cardiovascular disease in South Asians: application of FINRISK, Framingham and SCORE models to Newcastle Heart Project data," Journal of Public Health, vol. 27, no. 1, pp. 93-100, 2005.

[33] P. Deurenberg, M. Deurenberg-Yap, and S. Guricci, "Asians are different from Caucasians and from each other in their body mass index/body fat per cent relationship," Obesity Reviews, vol. 3, no. 3, pp. 141-146, 2002.

[34] S. Gurrici, Y. Hartriyanti, J. G. A. J. Hautvast, and P. Deurenberg, "Relationship between body fat and body mass index: differences between Indonesians and Dutch Caucasians," European Journal of Clinical Nutrition, vol. 52, no. 11, pp. 779-783, 1998.

[35] F. Faul, E. Erdfelder, A.-G. Lang, and A. Buchner, "G*Power 3: a flexible statistical power analysis program for the social, behavioral, and biomedical sciences," Behavior Research Methods, vol. 39, no. 2, pp. 175-191, 2007.

[36] T. V. Barreira, A. E. Staiano, and P. T. Katzmarzyk, "Validity assessment of a portable bioimpedance scale to estimate body fat percentage in White and African-American children and adolescents," Pediatric Obesity, vol. 8, no. 2, pp. E29-E32, 2013.

[37] P. Y. Sim, T. T. Su, H. Abd Majid, A. M. Nahar, and M. Y. Jalaludin, "A comparison study of portable foot-to-foot bioelectrical impedance scale to measure body fat percentage in Asian adults and children," BioMed Research International, vol. 2014, Article ID 475659, 10 pages, 2014.

[38] T. T. Su, P. Y. Sim, A. M. Nahar et al., "Association between selfreported physical activity and indicators of body composition in Malaysian adolescents," Preventive Medicine, vol. 67, pp. 100105, 2014.

[39] G. R. Letchuman, W. M. Wan Nazaimoon, W. B. Wan Mohamad et al., "Prevalence of diabetes in the Malaysian National Health Morbidity Survey III 2006," The Medical journal of Malaysia, vol. 65, no. 3, pp. 180-186, 2010.

[40] Ministry of Health, The Fourth National Health and Morbidity Survey (NHMS IV), Institute of Public Health, Putrajaya, Malaysia, 2011.

[41] Codes \& Classifications, http://www.statistics.gov.my/portal/ index.php? option $=$ com_content $\&$ view $=$ article \&id $=1492 \&$ Itemid=99\&lang=en.
[42] The HLS-EU Consortium, "Final report executive summary (D17)," The European Health Literacy Project (HLS-EU), 2012, http://www.maastrichtuniversity.nl/web/file?uuid=b994bc0bbf89-477c-af47-125cfbea4666\&owner=5113a977-24b4-40c896e3-4b38cf5e99f5.

[43] R. Rasiah, K. Yusoff, A. Mohammadreza et al., "Cardiovascular disease risk factors and socioeconomic variables in a nation undergoing epidemiologic transition," BMC Public Health, vol. 13 , no. 1 , article $886,2013$.

[44] Ministry of Health Malaysia, Report of the Second National Health and Morbidity Survey (NHMS II), Institute for Public Health, Ministry of Health Malaysia, Kuala Lumpur, Malaysia, 1996.

[45] Ministry of Health Malaysia, The Third National Health and Morbidity Survey (NHMS III), Institute of Public Health, 2006.

[46] M. Amiri, H. Majid, F. Hairi, N. Thangiah, A. Bulgiba, and T. Su, "Prevalence and determinants of cardiovascular disease risk factors among the residents of urban community housing projects in Malaysia," BMC Public Health, vol. 14, supplement 3, p. S3, 2014.

[47] C. M. Y. Lee, R. R. Huxley, R. P. Wildman, and M. Woodward, "Indices of abdominal obesity are better discriminators of cardiovascular risk factors than BMI: a meta-analysis," Journal of Clinical Epidemiology, vol. 61, no. 7, pp. 646-653, 2008.

[48] J. C. Seidell, T. S. Han, E. J. M. Feskens, and M. E. J. Lean, "Narrow hips and broad waist circumferences independently contribute to increased risk of non-insulin-dependent diabetes mellitus," Journal of Internal Medicine, vol. 242, no. 5, pp. 401406, 1997.

[49] R. J. Garrison and W. P. Castelli, "Weight and thirty-year mortality of men in the Framingham Study," Annals of Internal Medicine, vol. 103, no. 6, part 2, pp. 1006-1009, 1985.

[50] J. E. Manson, G. A. Colditz, M. J. Stampfer et al., "A prospective study of obesity and risk of coronary heart disease in women," The New England Journal of Medicine, vol. 322, no. 13, pp. 882889, 1990.

[51] S. W. Rabkin, F. A. L. Mathewson, and P. H. Hsu, "Relation of body weight to development of ischemic heart disease in a cohort of young North American men after a 26 year observation period: the Manitoba study," The American Journal of Cardiology, vol. 39, no. 3, pp. 452-458, 1977.

[52] H. Schulte, A. von Eckardstein, P. Cullen, and G. Assmann, "Overweight and cardiovascular risk," Herz, vol. 26, no. 3, pp. 170-177, 2001.

[53] T. S. Han, F. C. H. Bijnen, M. E. J. Lean, and J. C. Seidell, "Separate associations of waist and hip circumference with lifestyle factors," International Journal of Epidemiology, vol. 27, no. 3, pp. 422-430, 1998.

[54] B. D. Cox, M. J. Whichelow, and A. T. Prevost, "The development of cardiovascular disease in relation to anthropometric indices and hypertension in British adults," International Journal of Obesity, vol. 22, no. 10, pp. 966-973, 1998.

[55] M. Higgins, W. Kannel, R. Garrison, J. Pinsky, and J. Stokes III, "Hazards of obesity-the Framingham experience," Acta Medica Scandinavica, vol. 222, supplement 723, pp. 23-26, 1987.

[56] W. B. Kannel, L. A. Cupples, R. Ramaswami, J. Stokes III, B. E. Kreger, and M. Higgins, "Regional obesity and risk of cardiovascular disease; the framingham study," Journal of Clinical Epidemiology, vol. 44, no. 2, pp. 183-190, 1991.

[57] W. Y. Lin, L. T. Lee, C. Y. Chen et al., "Optimal cut-off values for obesity: using simple anthropometric indices to predict 
cardiovascular risk factors in Taiwan," International Journal of Obesity, vol. 26, no. 9, pp. 1232-1238, 2002.

[58] M. Dalton, A. J. Cameron, P. Z. Zimmet et al., "Waist circumference, waist-hip ratio and body mass index and their correlation with cardiovascular disease risk factors in Australian adults," Journal of Internal Medicine, vol. 254, no. 6, pp. 555-563, 2003.

[59] S. Murray, "Is waist-to-hip ratio a better marker of cardiovascular risk than body mass index?" Canadian Medical Association Journal, vol. 174, no. 3, p. 308, 2006.

[60] C. I. Ardern, P. T. Katzmarzyk, I. Janssen, and R. Ross, “Discrimination of health risk by combined body mass index and waist circumference," Obesity Research, vol. 11, no. 1, pp. 135-142, 2003.

[61] D. C. Chan, G. F. Watts, P. H. R. Barrett, and V. Burke, "Waist circumference, waist-to-hip ratio and body mass index as predictors of adipose tissue compartments in men," Quarterly Journal of Medicine, vol. 96, no. 6, pp. 441-447, 2003.

[62] L. Foucan, J. Hanley, J. Deloumeaux, and S. Suissa, "Body mass index (BMI) and waist circumference (WC) as screening tools for cardiovascular risk factors in Guadeloupean women," Journal of Clinical Epidemiology, vol. 55, no. 10, pp. 990-996, 2002.

[63] R. W. Taylor, D. Keil, E. J. Gold, S. M. Williams, and A. Goulding, "Body mass index, waist girth, and waist-to-hip ratio as indexes of total and regional adiposity in women: evaluation using receiver operating characteristic curves," American Journal of Clinical Nutrition, vol. 67, no. 1, pp. 44-49, 1998.

[64] J. M. Dorn, E. F. Schisterman, W. Winkelstein Jr., and M. Trevisan, "Body mass index and mortality in a general population sample of men and women: the Buffalo health study," The American Journal of Epidemiology, vol. 146, no. 11, pp. 919-931, 1997.

[65] M. Ferland, J.-P. Despres, A. Tremblay et al., "Assessment of adipose tissue distribution by computed axial tomography in obese women: association with body density and anthropometric measurements," The British Journal of Nutrition, vol. 61, no. 2, pp. 139-148, 1989.

[66] A. De Lorenzo, A. Nardi, L. Iacopino et al., "A new predictive equation for evaluating women body fat percentage and obesity-related cardiovascular disease risk," Journal of Endocrinological Investigation, vol. 37, no. 6, pp. 511-524, 2014.

[67] P. K. Myint, C. S. Kwok, R. N. Luben, N. J. Wareham, and K.T. Khaw, "Body fat percentage, body mass index and waist-tohip ratio as predictors of mortality and cardiovascular disease," Heart, vol. 100, no. 20, pp. 1613-1619, 2014.

[68] H.-H. Chuang, W.-C. Li, B.-F. Sheu et al., "Correlation between body composition and risk factors for cardiovascular disease and metabolic syndrome," BioFactors, vol. 38, no. 4, pp. 284291, 2012. 


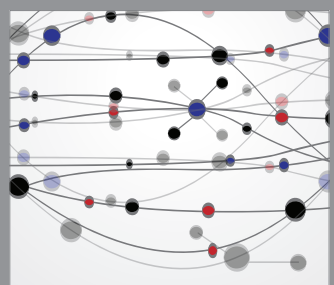

The Scientific World Journal
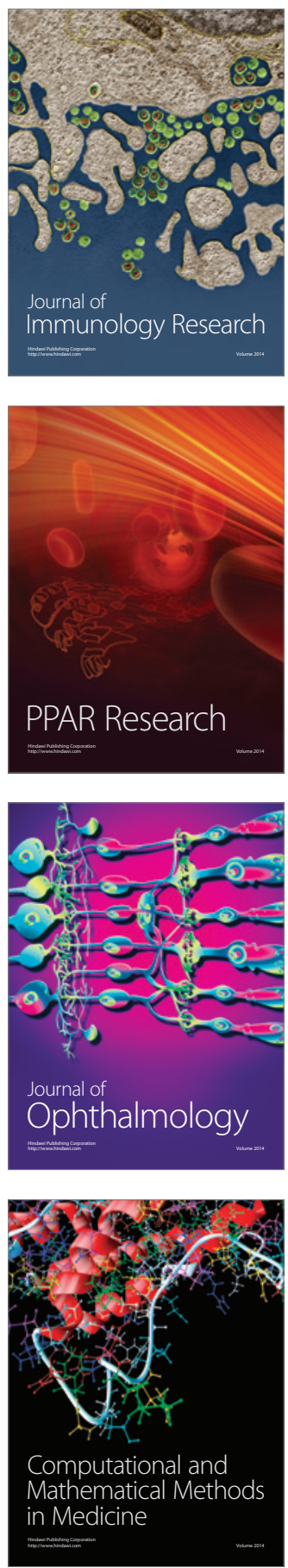

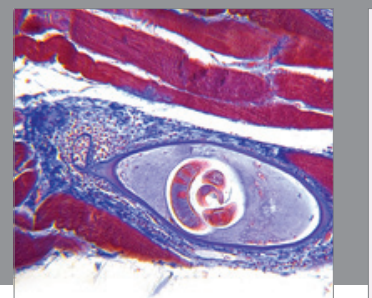

Gastroenterology

Research and Practice
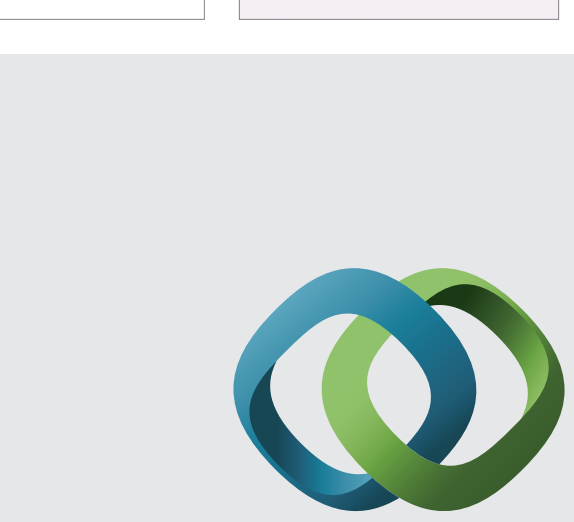

\section{Hindawi}

Submit your manuscripts at

http://www.hindawi.com
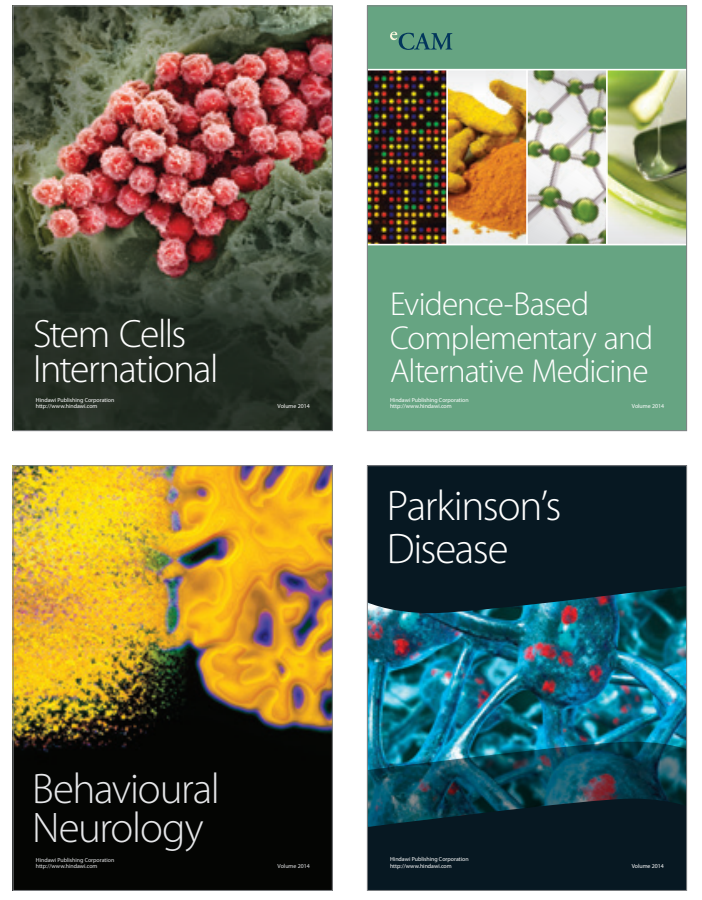
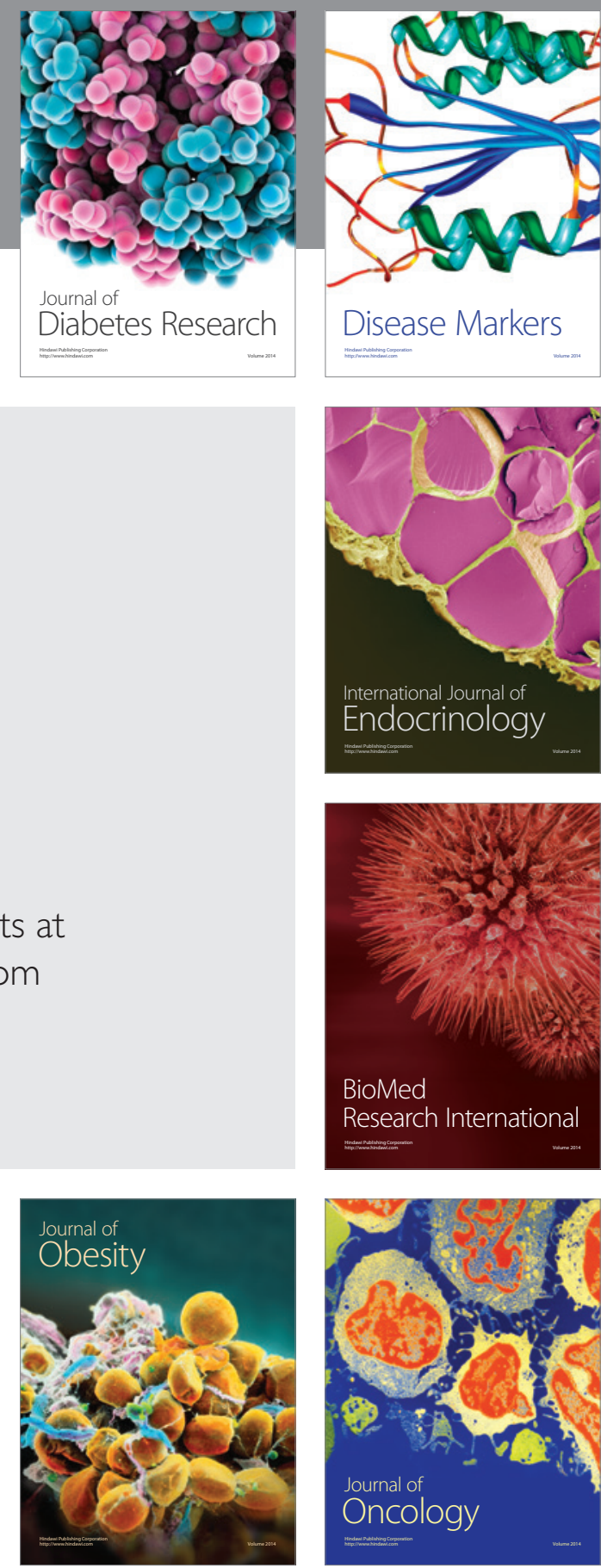

Disease Markers
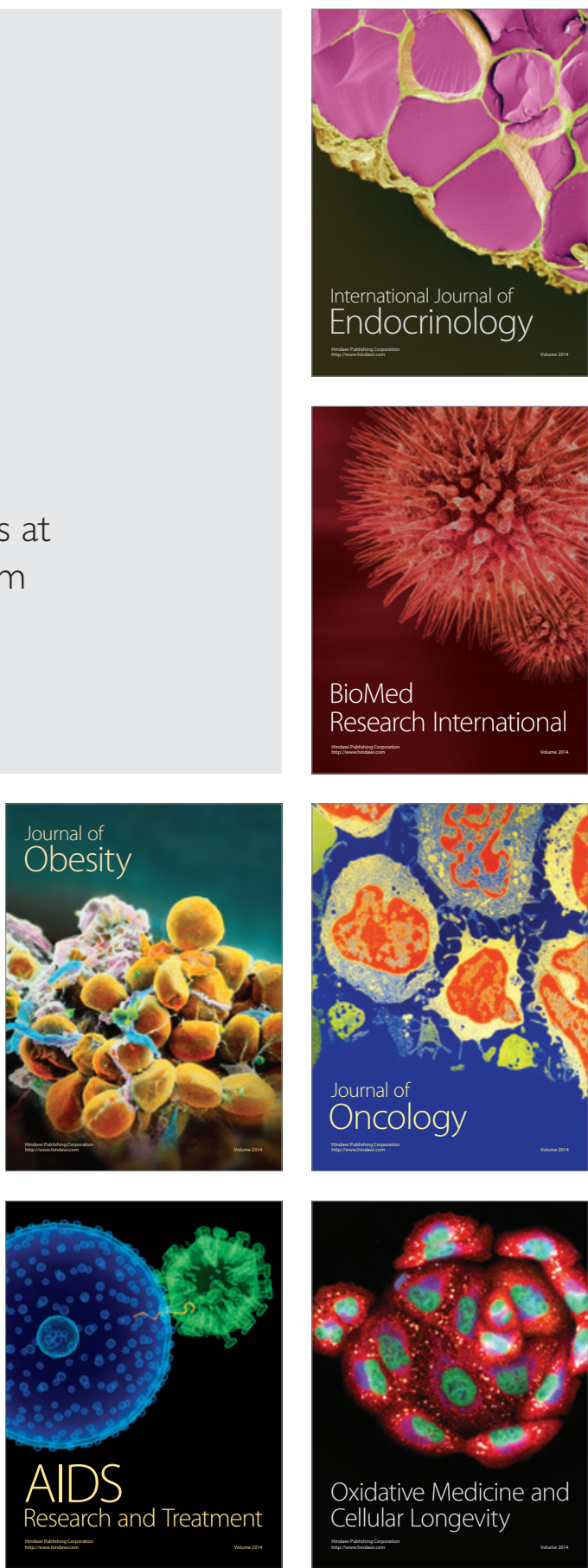